\title{
KEPUASAN KONSUMEN DALAM BELANJA SAYURAN SECARA ONLINE DI PO. ELLFAZ FRUITS \& VEGETABLES DI KECAMATAN BANDUNGAN
}

\author{
CUSTOMER SATISFACTION IN SHOPPING VEGETABLES ONLINE \\ AT PO. ELLFAZ FRUITS \& VEGETABLES IN BANDUNGAN DISTRICT
}

\author{
Febryanna Savitri*, Bayu Nuswantara \\ Program Studi Agribisnis, Fakultas Pertanian dan Bisnis, UKSW Salatiga \\ *Email: 522017045@student.uksw.edu \\ (Diterima 22-09-2021; Disetujui 15-12-2021)
}

\begin{abstract}
ABSTRAK
Saat ini belanja online menjadi cara yang populer dikalangan masyarakat, hal ini dapat dilihat dengan berkembangnya proses jual beli sayuran secara online yang semakin mempermudah konsumen untuk membeli sayuran. Konsumen dapat berbelanja kapanpun dan dimanapun dengan mudah. Tujuan dari penelitian ini untuk mengetahui gambaran karakteristik konsumen sayuran terhadap kepuasan dalam belanja sayuran secara online dan mengatahui tingkat kepuasan berdasarakan dimensi kepuasan konsumen. Metode penelitian yang digunakan adalah penelitian deskriptif kuantitatif dengan teknik pengambilan sampel purposive sampling sebanyak 60 responden konsumen PO Ellfaz Fruits \& Vegetables. Dengan teknik analisis data yang digunakan adalah metode CSI (Customer Satisfaction Index) dan metode IPA (Importance Performance Analysis). Hasil dari penelitian ini menunjukkan bahwa aribut kesegaran harus diprioritaskan untuk diperbaiki sehingga kinerja atribut ini meningkat dan memenuhi harapan konsumen.
\end{abstract}

Kata kunci: sayuran, kepuasan konsumen, customer satisfaction index, importance performance analysis

\section{ABSTRACT}

Currently online shopping is becoming a populer way among the public, this can be seen by the development of the process of buying and selling vegetables online that makes it easier for consumers to buy vegetables. Consumers can shop anytime and anywhere easily. The purpose of this study is to find out the characteristics of vegetable consumers to satisfaction in shopping vegetables online and know the level of satisfaction based on the dimension of consumer satisfaction. The research method used is quantitative descriptive research with purposive sampling techniques as many as 60 respondents of PO Ellfaz Fruits \&Vegetables PO consumers. With data analysis techniques used are CSI (Customer Satisfaction Index) method and IPA (Importance Performance Analysis) method. The results of this study show that freshness aribut should be prioritized to be improved so that the performance of these attributes increases and meets consumer expectations.

Keywords: vegetables, customer satisfaction, customer satisfaction index, importance performance analysis

\section{PENDAHULUAN}

Dengan perkembangan teknologi di Indonesia saat ini yang dapat memberikan jaringan bisnis tanpa batas. Pemanfaatan internet ini tidak hanya untuk lahan mencari informasi saja melainkan dimanfaatkan sebagai lahan bisnis untuk melakukan transaksi perdagangan tanpa terikat ruang dan waktu. Belanja online merupakan salah 
satu cara yang populer di kalangan masyarakat pada saat ini, hal ini dapat dilihat dengan seiring meningkatnya pula jumlah transaksi belanja online yang telah dilakukan. Menurut Ernst dan Young (1999) dalam Ching dan Dolakia (2003), kenyamanan dan penghemat yang menjadi dua alasan meningkatnya minat belanja online bagi konsumen.

Menurut BPS (2016), tren konsumsi sayuran menunjukkan keterkaitan antara penghasilan dan pola makan penduduk. Penduduk dengan penghasilan rendah mengonsumsi sayuran dalam jumlah yang sangat sedikit dan konsumsi akan mengalami peningkatan seiring dengan meningkatnya penghasilan. Namun, hal ini tidak menjadi masalah bagi beberapa konsumen yang mulai sadar terhadap kesehatan, kesadaran akan hidup sehat ini menyababkan adanya peningkatan permintaan konsumen terhadap sayuran.

Kehadiran tren berbelanja secara online sejak tahun 2010 menjadi alternatif bagi masyarakat dalam memenuhi kebutuhanya. Disamping adanya online shopping, terdapat juga penjualan offline seperti pasar tradisional maupun pasar modern yang sangat berbeda dengan online shopping, jika dilihat dari sisi waktu dan kemudahan online shopping lebih mudah dan menghemat banyak waktu dari pada belanja secara offline konsumen pun dapat berbelanja kapanpun dan dimanapun dengan mudah.

PO. Ellfaz Fruits \& Vegetables salah satunya perusahaan perseorangan yang merupakan supplier berbagai jenis sayuran dan buah sehat yang melayani pembelian sayuran secara online. Sayuran yang dipasarkan di PO. Ellfaz Fruits \& Vegetables pada keadaan segar dan memiliki kualitas yang baik.

Dalam kepuasan konsumen terdapat beberapa dimensi kepuasan yang pertama adalah kualitas produk. Untuk memberikan kepuasan terhadap konsumen, produsen harus memasarkan produknya dengan kinerja atribut produk melalui kualitas produk yang tinggi dengan harga yang sesuai. Menurut Tjiptono (2008), kualitas adalah suatu kondisi dinamis yang berhubungan dengan produk yang dapat memenuhi atau melebihi harapan. Faktor lainya adalah kualitas pelayanan, kualitas pelayanan menjadi salah satu ukuran atas keberhasilan dalam memberikan jaminan atas kepuasan konsumen, Konsumen yang menentukan berkualitas atau tidaknya suatu pelayanan. Dengan demikian baik tidaknya kualitas 
pelayanan tergantung pada kemampuan penyedia jasa dalam memenuhi harapan pelanggannya secara konsisten (Tjiptono, 2006).

Faktor harga juga berperan dalam kepuasan pembelian sayuran secara online Harga juga sebagai indikator nilai dalam penentuan kepuasan konsumen, dimana indikator tersebut dihubungkan dengan manfaat yang dirasakan (Tjiptono, 2001). Berdasarkan latar belakang tersebut dapat dirumuskan permasalahan penelitian yaitu, mengenali atribut-atribut apa saja yang disukai oleh konsumen dalam belanja sayuran secara online. Sedangkan tujuan dari penelitian ini adalah atribut-atribut yang disukai oleh konsumen dalam belanja sayuran secara online.

\section{METODE PENELITIAN}

Penelitian dilakukan di PO. Ellfas Vegetables, Dusun Jibaran, Rt 02/ Rw 02, Desa Jimbaran Kecamatan Bandungan. Pemilihan lokasi penelitian ini dalukan secara sengaja (purposive) berdasarkan pertimbangan tertentu yang disesuaikan dengan tujuan penelitian.

Jenis penelitian ini adalah deskriptif kuantitatif. Penelitian ini digunakan untuk menganalisi data dengan cara mendeskripsikan atau menggambarkan data yang terkumpul sebagaimana adanya tanpa bermaksud membuat kesimpulan yang berlaku untuk umum dan generaliisasi (Sugiyono, 2012).

Berdasarkan jenis penelitian, penelitian ini menggunakan metode penelitian survei, yaitu metode yang digunakan untuk memperoleh data dari tempat tertentu yang alamiah, peneliti melakukan pengumpulan data dengan kuesioner, tes, wawancara terstruktur dan sebagainya (Sugiyono, 2012).

Adapun metode yang digunakan dalam penelitian ini adalah Purposive sampling. Purposive sampling merupakan teknik penentuan sampel dengan pertimbangan tertentu (Sugiyono, 2011). Dalam penarikan sampel, terlebih dahulu mengetahui jumlah populasi yang ada dalam penelitian. Populasi dalam penelitian ini adalah seluruh konsumen yang membeli dan pernah membeli produk dari Po. Ellfas Vegetables yang jumlahnya tidak diketahui.

Berdasarkan pedoman dari Sugiyono (2011), maka jumlah sampel yang dikumpulkan dalam penellitian sebanyak 60 responden. Terdapat tiga variabel bebas (independent) dan satu varaiabel terikat (dependent) penelitian ini yang dikalikan dari jumlah variabel yang diteliti. 
Data yang dihasilkan dalam penelitian ini dianalisis menggunakan Customer Satisfaction Index (CSI) dan Importance-Performance Analysis (IPA) sebagai berikut:

\section{Customer Satisfaction Index (CSI)}

CSI digunakan untuk mengukur tingkat kepuasan konsumen terhadap atribut produk sayuran yang dapat digunakan sebagai acuan untuk menentukan strategi usaha di masa yang akan datang. Pengukuran CSI pada konsumen sendiri melalui riset konsumen dapat mengidentifikasi sumber yang terjadi kepuasan dan ketidak puasan (Irawan, 2003). Adapun metode pengukuran menurut Guswanto, dkk (2012) sebagai berikut:

a. Menghitung weighting factors, yaitu mengubah nilai rata-rata tingkat kepentingan menjadi angka persentase dari total rata-rata tingkat kepentingan seluruh variabel yang diuji, sehingga didapatkan total:

Weighting Factors 100\%.

$\mathrm{WF}=\frac{R S P}{\sum R S P} \times 100 \%$

Keterangan:

$\mathrm{WF}=$ weighting factors $(\%)$

$\mathrm{RSP}=$ rata-rata skor kepentingan

b. Menghitung weighting scored (WS), yaitu nilai perkalian antar rata-rata tingkat kinerja/kepuasan masing- masing variabel dengan weighting factors $(W F)$ masing-masing variabel.

$\mathrm{WS}=\mathrm{RSK} \times \mathrm{WF}$

Keterangan:

$\mathrm{WF}=$ weighting factors $(\%)$

$\mathrm{RSK}=$ rata-rata skor kinerja

c. Menghitung Weighting Total (WT) yaitu menjumlahkan weighting scored dari semua variabel kualitas jasa pelayanan.

$\mathrm{WT}=\mathrm{WS}_{1}+\mathrm{WS}_{2}+\mathrm{WS}_{3}+\ldots \mathrm{WS}_{\mathrm{n}}$

Keterangan:

$\mathrm{WS}_{1}=$ weighting factors ke 1

$\mathrm{WS}_{\mathrm{n}}=$ weighting factors ke $n$

d. Menghitung satisfaction index (SI), yaitu Weighting Total (WT) dibagi skala maksimal yang digunakan kemudian dikali 100\%.

$$
\begin{aligned}
& \mathrm{CSI}=\frac{\text { WT }}{\text { Skor Maksimal }} \times 100 \% \\
& \text { Indikator untuk mengukur }
\end{aligned}
$$
kepuasan konsumen tersaji pada Tabel 1.

Tabel 1. Kriteria Indeks Kepuasan Konsumen

\begin{tabular}{l|l}
\hline Nilai CSI & Kriteria CSI \\
\hline $0<\mathrm{CSI} \leq 20 \%$ & Sangat tidak puas \\
$20 \%<\mathrm{CSI} \leq 40 \%$ & Tidak puas \\
$40 \%<\mathrm{CSI} \leq 60 \%$ & Cukup puas \\
$60 \%<\mathrm{CSI} \leq 80 \%$ & Puas \\
$80 \%<\mathrm{CSI} \leq 100 \%$ & Sangat puas \\
\hline
\end{tabular}

2. Importance Performance Analysis (IPA)

Importance Performance Analysis adalah suatu teknik analisis yang 
digunakan untuk mengidentifikasi faktorfaktor kinerja penting apa saja yang harus ditunjukkan oleh suatu organisasi dalam memenuhi kepuasan konsumen. Martila dan James dalam Supranto (2006) mengemukakan bahwa analisis tingkat kepentingan kerja merupakan suatu teknik terapan yang mudah untuk mengukur tingkat kepentingan dan tingkat kinerja atau pelaksana atribut.

Pertama untuk mengetahui posisi masing-masing atribut menggunakan perhitungan nilai rata-rata dari persepsi konsumen terhadap tingkat kepentingan dan tingkat kinerja dari setiap atribut, dengan rumus sebagai berikut:

$$
\overline{\bar{X}}=\frac{\sum \mathrm{xi}}{\mathrm{n}} ; \overline{\bar{Y}}=\frac{\sum \mathrm{yi}}{\mathrm{n}}
$$

\section{Keterangan:}

$\mathrm{X}=$ rata - rata skor tingkat kinerja

$\mathrm{Y}=$ Rata- rata skor tingkat kepentingan

$\mathrm{n}=$ Jumlah sampel yang digunakan

Kedua, menghitung rata-rata skor tingkat kepentingan dan kinerja dari setiap atribut. Nilai rata-rata tersebut digunakan sebagai batasan dalam diagram kartesius. Berikut persamaan yang digunakan dalam menentukan batas diagram kartesius.

$$
\overline{\bar{X}}=\frac{\sum \mathrm{xi}}{\mathrm{n}} ; \overline{\bar{Y}}=\frac{\sum \mathrm{yi}}{\mathrm{n}}
$$

Keterangan:

$\overline{\bar{X}}=$ Rata-rata skor tingkat kinerja
$\overline{\bar{Y}}=$ Rata-rata skor tingkat kepentingan

$\mathrm{n}=$ Jumlah sampel yang digunakan

Menurut Rangkuti (2003), interpretasi dari kuadaran tersebut sebagai berikut:

1. Kuadran I (Prioritas Utama)

Kuadran ini mewakili faktor-faktor yang dinilai konsumen memiliki nilai kepentingan yang tinggi, tetapi faktor-faktor tersebut nilai kinerja yang belum selesai dengan harapan konsumen.

2. Kuadran II (Pertahankan Prestasi)

Kuadran ini merupakan wilayah yang memuat faktor-faktor yang dinilai konsumen memiliki kepentingan yang tinggi dan faktor-faktor tersebut telah melebihi harapan konsumen.

3. Kuadran III (Prioritas Rendah)

Kuadran ini mewakili faktor-faktor yang dinilai konsumen memiliki nilai kepentingan yang rendah dan kinerja dari faktor tersebut dinilai belum sesuai dengan harapan konsumen.

4. Kuadran IV (Berlebihan)

Kuadran ini merupakan wilayah yang memuat faktor-faktor yang dinilai konsumen memiliki kepentingan yang rendah, tetapi konsumen menilai bahwa faktor tersebut melebihi harapan konsumen. 


\section{HASIL DAN PEMBAHASAN}

\section{Karakteristik Responden}

Karakteristik umum konsumen sayuran di PO. Ellfaz Fruits \& Vegetables digambarkan pada jenis kelamin, umur, pendidikan terakhir, pekerjaan dan pendapatan perbulan.

\section{Jenis Kelamin}

Tabel 1. Jenis Kelamin

\begin{tabular}{cccc}
\hline \multirow{2}{*}{ No. } & Jenis & \multicolumn{2}{c}{ Jumlah } \\
\cline { 3 - 4 } & Kelamin & Orang & Presentase (\%) \\
\hline 1 & $\mathrm{~L}$ & 6 & 10 \\
2 & $\mathrm{P}$ & 54 & 90 \\
\hline \multicolumn{2}{c}{ Jumlah } & 60 & 100 \\
\hline
\end{tabular}

Sumber : Data Primer, 2021 (diolah)

Berdasarkan Tabel 1 dapat dilihat bahwa responden yang membeli sayuran di PO Ellfaz fruits \& Vegetables didominasi oleh responden perempuan sebesar 90\% dibandingkan laki-laki yang hanya sebesar $10 \%$. Berdasarkan hasil penelitian yang terdapat dilapangan terbukti bahwa yang memahami kebutuhan pokok sebagian besar adalah perempuan.

\section{Usia}

Tabel 2. Usia

\begin{tabular}{cccc}
\hline \multirow{2}{*}{ No. } & Usia & \multicolumn{2}{c}{ Jumlah } \\
\cline { 3 - 4 } & (tahun) & Orang & Presentase (\%) \\
\hline 1 & $22-31$ & 28 & 47 \\
2 & $32-41$ & 12 & 20 \\
3 & $42-51$ & 6 & 10 \\
4 & $52-61$ & 13 & 22 \\
5 & $62-71$ & 1 & 1 \\
\hline \multicolumn{2}{c}{ Jumlah } & 60 & 100 \\
\hline
\end{tabular}

Sumber : Data Primer, 2021 (diolah)

Pada tabel 2, responden pembeli sayuran di PO Ellfaz Fruits \& Vegetables terbanyak pada usia 22-31 tahun yaitu sebanyak 47\%. Ini menunjukkan bahwa konsumen yang menjadi responden sayuran di PO Ellfaz Fruits \& Vegetables dalam penelitian ini berada pada masa usia produktif.

\section{Pendidikan Terakhir}

Tabel 3. Pendidikan Terakhir

\begin{tabular}{clcc}
\hline \multirow{2}{*}{ No } & Pendidikan & \multicolumn{2}{c}{ Jumlah } \\
\cline { 3 - 4 } & Terakhir & Orang & Presentase (\%) \\
\hline 1 & SD & 0 & 0 \\
2 & SMP & 1 & 2 \\
3 & SMA & 12 & 20 \\
& Diploma atau & & \\
& Sarjana (S1, & & \\
4 & S2 atau S3) & 47 & 78 \\
\hline & Jumlah & 60 & 100 \\
\hline
\end{tabular}

Sumber : Data Primer, 2021 (diolah)

Tingkah laku sesorang sangat dipengaruhi oleh tingkat pendidikan yang telah dicapai. Sesorang yang berpendidikan tinggi cenderung akan memilih bahan makanan yang berkualitas dan lebih baik bagi kesehatan. Pada Tabel 3 menunjukan bahwa responden sayuran di PO Ellfaz Fruits \& Vegetables terbanyak berpendidikan terakhir diploma ataupun sarjana yaitu sebesar $78 \%$.

\section{Pekerjaan}

Jenis pekerjaan akan mempengaruhi cara berfikir sesorang dalam memilih produk yang terbaik untuk dikonsumsi pada saat ini. Dapat dilihat Tabel 4 terdapat lima kategori jenis pekerjaan dari responden yaitu pelajar/mahasiswa, PNS/ABRI, pegawai 
swasta, ibu rumah tangga dan wiraswasta.

Kategori PNS/ABRI merupakan jenis pekerjaan terbanyak dari responden sayuran di PO Ellfaz Fruits \& Vegetables yaitu sebesar $33 \%$.

Tabel 4. Pekerjaan

\begin{tabular}{clcc}
\hline \multirow{2}{*}{ No } & Pekerjaan & \multicolumn{2}{c}{ Jumlah } \\
\cline { 3 - 4 } & & Orang & Presentase (\%) \\
\hline 1 & Pelajar/ & 5 & 8 \\
& Mahasiswa & & 33 \\
2 & PNS/ABRI & 20 & 17 \\
3 & Pegawai & 10 & 22 \\
& Swasta & & \\
4 & Ibu rumah & 13 & 20 \\
& tangga & & 100 \\
5 & Wiraswasta & 12 &
\end{tabular}

Sumber : Data Primer, 2021 (diolah)

\section{Pendapatan}

Tabel 5. Pendapatan

\begin{tabular}{|c|c|c|c|}
\hline \multirow{2}{*}{ No } & \multirow{2}{*}{ Pendapatan } & \multicolumn{2}{|r|}{ Jumlah } \\
\hline & & Orang & Presentase $(\%)$ \\
\hline 1 & $\begin{array}{l}\text { Dibawah Rp } \\
2.500 .000\end{array}$ & 18 & 30 \\
\hline 2 & $\begin{array}{l}\text { Rp } 2.500 .000- \\
\operatorname{Rp} 5.000 .000\end{array}$ & 18 & 30 \\
\hline 3 & $\begin{array}{l}\text { Di atas Rp } \\
5.000 .000\end{array}$ & 24 & 40 \\
\hline & Jumlah & 60 & 100 \\
\hline
\end{tabular}

Sumber : Data Primer, 2021 (diolah)

Dapat dilihat pada Tabel 5, pendapatan responden sayuran di PO Ellfaz Fruits \& Vegetables didominasi di atas $\mathrm{Rp} 5.000 .000$, yaitu sebesar 40\%. Rp 5.000 .000 , yaitu sebesar 40\%. Semakin besar pendapatan maka semakin besar pula kemampuan konsumen dalam membeli beragam kebutuhannya termasuk dalam pembelian sayuran yang akan dikonsumsi.

\section{Uji Validitas dan Uji Reliabilitas}

Hasil uji validitas dapat dilihat pada Tabel 6 dan 7.

\begin{tabular}{|c|c|c|c|}
\hline Item & $\begin{array}{c}\text { Nilai } \\
\text { Korelasi }\end{array}$ & $\begin{array}{l}\mathrm{R} \text { tabel } \\
(\alpha 5 \%)\end{array}$ & $\begin{array}{l}\text { Kete- } \\
\text { rangan }\end{array}$ \\
\hline Keragaman & 0,504 & 0,254 & Valid \\
\hline $\begin{array}{l}\text { Kualitas } \\
\text { Produk }\end{array}$ & 0,617 & 0,254 & Valid \\
\hline $\begin{array}{l}\text { Kesegaran } \\
\text { Produk }\end{array}$ & 0,475 & 0,254 & Valid \\
\hline $\begin{array}{l}\text { Tampilan } \\
\text { Produk }\end{array}$ & 0,289 & 0,254 & Valid \\
\hline Kemudahan & 0,497 & 0,254 & Valid \\
\hline Kecepatan & 0,622 & 0,254 & Valid \\
\hline Keramahan & 0,629 & 0,254 & Valid \\
\hline $\begin{array}{l}\text { Ukuran } \\
\text { Produk }\end{array}$ & 0,681 & 0,254 & Valid \\
\hline Harga & 0,287 & 0,254 & Valid \\
\hline Jaminan & 0,330 & 0,254 & Valid \\
\hline
\end{tabular}

Sumber : Data Primer, 2021 (diolah)

\begin{tabular}{lccc} 
Tabel 7. & \multicolumn{2}{c}{$\begin{array}{c}\text { Uji } \\
\text { Kinerja/Persepsi }\end{array}$} & $\begin{array}{c}\text { Validitas } \\
\text { Penilaian }\end{array}$ \\
\hline \multicolumn{1}{c}{ Item } & $\begin{array}{c}\text { Nilai } \\
\text { Korelasi }\end{array}$ & $\begin{array}{c}\text { R tabel } \\
(\alpha 5 \%)\end{array}$ & $\begin{array}{c}\text { Kete- } \\
\text { rangan }\end{array}$ \\
\hline Keragaman & 0,389 & 0,254 & Valid \\
$\begin{array}{l}\text { Kualitas } \\
\text { Produk }\end{array}$ & 0,634 & 0,254 & Valid \\
$\begin{array}{l}\text { Kesegaran } \\
\text { Produk }\end{array}$ & 0,700 & 0,254 & Valid \\
$\begin{array}{l}\text { Tampilan } \\
\text { Produk }\end{array}$ & 0,576 & 0,254 & Valid \\
Kemudahan & 0,564 & 0,254 & Valid \\
Kecepatan & 0,753 & 0,254 & Valid \\
Keramahan & 0,680 & 0,254 & Valid \\
$\begin{array}{l}\text { Ukuran } \\
\text { Produk }\end{array}$ & 0,465 & 0,254 & Valid \\
Harga & 0,629 & 0,254 & Valid \\
Jaminan & 0,480 & 0,254 & Valid \\
\hline
\end{tabular}

Sumber : Data Primer, 2021 (diolah)

Masing-masing indikator dari variabel tingkat kepentingan dan kinerja terhadap kepuasan konsumen masingmasing mendapatkan nilai hasil uji validitas koefisien korelasi lebih besar 
dari $r_{\text {tabel }}$. Dengan $n=60$ pada tingkat kepercayaan $0,05 \% \mathrm{r}_{\text {tabel }}=0,254$ sehingga pengujian variabel pada tingkat kepentingan dan kinerja terhadap kepuasan konsumen dapat dinyatakan valid dan dapat dilanjutkan untuk pengujian selanjutnya.

Hasil uji reliabilitas dapat dilihat pada Tabel 8, diketahui bahwa tingkat kepentingan dan kinerja terhadap kepuasan konsumen semua item dikatakan reliabel karena nilai dari cronbach alpha lebih besar dari 0,06.

\begin{tabular}{cccc}
\multicolumn{4}{c}{ Tabel 8. Uji Reliabilitas } \\
\hline Item & $\begin{array}{c}\text { Cronbach's } \\
\text { Alpha }\end{array}$ & $\begin{array}{c}\text { R } \\
\text { Kritis }\end{array}$ & $\begin{array}{c}\text { Kete- } \\
\text { rangan }\end{array}$ \\
\hline Kepentingan & 0,651 & 0,06 & Reliabel \\
Kinerja & 0,787 & 0,06 & Reliabel \\
\hline \multicolumn{4}{c}{ Sumber : Data Primer, } \\
& 2021 (diolah)
\end{tabular}

\section{B. Customer Satisfaction Index (CSI)}

Kepuasan konsumen terhadap produk sayuran pada penelitian ini dianalisis menggunakan CSI yang memperhitungkan nilai rata-rata kepentingan suatu atribut dalam menentukan tingkan kinerja atribut yang nantinya akan memberikan pengaruh terhadap tingkat kepuasan konsumen. Rumus nilai CSI sebagai berikut:

$$
\begin{aligned}
\mathrm{CSI} & =\frac{395}{5} \times 100 \% \\
& =78,97 \%
\end{aligned}
$$

Hasil perhitungan Customer Satisfaction Index (CSI) sayuran di PO Ellfaz Fruits \& Vegetables ditampilkan pada Tabel 9. Nilai Customer Satisfaction Index (CSI) pada PO Ellfaz Fruits \& Vegetables sebesar 78,97 \% yang berada pada kriteria puas dengan atribut sayuran di PO Ellfaz Fruits \& Vegetables, dan sisanya $21,03 \%$ konsumen merasa belum puas dengan atribut sayuran yang ada.

\begin{tabular}{|c|c|c|c|c|}
\hline Atribut & $\begin{array}{c}\text { Mean } \\
\text { Importance } \\
\text { Score MIS }\end{array}$ & $\begin{array}{c}\text { Mean } \\
\text { Satisfaction } \\
\text { Score MSS }\end{array}$ & $\begin{array}{c}\text { Weight } \\
\text { Factors WF } \\
\text { (MIS/Total MIS) }\end{array}$ & $\begin{array}{c}\text { Weight Score WS } \\
\text { (WF x MSS) }\end{array}$ \\
\hline Keragaman & 4.37 & 4.18 & 10.6 & 44 \\
\hline Kualitas Produk & 4.32 & 4.02 & 10.5 & 42 \\
\hline Kesegaran Produk & 4.18 & 3.93 & 10.1 & 40 \\
\hline Tampilan Produk & 4.02 & 3.6 & 9.73 & 35 \\
\hline Kemudahan & 4.27 & 3.97 & 10.3 & 41 \\
\hline Kecepatan & 4.05 & 4.07 & 9.81 & 40 \\
\hline Keramahan & 4.17 & 4.18 & 10.09 & 42 \\
\hline Ukuran Produk & 3.85 & 3.63 & 9.33 & 34 \\
\hline Harga & 4.1 & 4.07 & 9.93 & 40 \\
\hline Jaminan & 3.97 & 3.78 & 9.61 & 36 \\
\hline Jumlah & 41.28 & & & \\
\hline CSI & \multicolumn{4}{|c|}{$78.97 \%$} \\
\hline
\end{tabular}

Tabel 9. Hasil perhitungan Customer Satisfaction Index (CSI)

Sumber: Data Primer, 2021 (diolah) 


\section{Importance Performance Analysis (IPA)}

Importance Performance Analysis (IPA) bertujuan untuk mengetahui atribut-atribut produk sayuran di PO Ellfaz Fruits \& Vegetables yang harus diperbaiki. Pengukuran atribut-atribut tersebut diperlukan untuk membandingkan antara kepentingan dan kinerja dengan menggunakan diagram katesius. Dengan diagram kartesius akan dibagi menjadi empat kuadran dan tiap kuadaran memiliki kondisi yang berbedabeda (Tabel 10).

Tabel 10. Nilai rata-rata atribut berdasarkan tingkat kepentingan dan kinerja

\begin{tabular}{clrl}
\hline No & \multicolumn{1}{c}{ Atribut } & Harapan & Kinerja \\
\hline \multicolumn{1}{l}{ Kualitas Produk } & & \\
\hline 1 & Keragaman & 4.37 & 4.18 \\
& Kulaitas & & \\
2 & Produk & 4.32 & 4.02 \\
3 & Kesegaran & 4.18 & 3.93 \\
4 & Tampilan & 4.02 & 3.60 \\
5 & Ukuran & 3.85 & 3.63 \\
\cline { 3 - 4 }
\end{tabular}

\begin{tabular}{|c|c|c|c|}
\hline \multicolumn{4}{|c|}{ Kualitas Produk } \\
\hline 6 & Kecepatan & 4.05 & 4.07 \\
\hline 7 & Keramahan & 4.17 & 4.18 \\
\hline 8 & Kemudahan & 4.27 & 3.97 \\
\hline 9 & Jaminan & 3.97 & 3.78 \\
\hline \multicolumn{4}{|c|}{ Harga } \\
\hline & Harga & 4.10 & 4.07 \\
\hline & Jumlah & 41.28 & 39.43 \\
\hline & Rata-rata & 4.13 & 3.94 \\
\hline
\end{tabular}

Sumber: Data Primer, 2021 (diolah)

Skor rata-rata dari tingkat kinerja atau persepsi (x) dan skor rata-rata dari tingkat harapan atau kepentingan (y) untuk menentukan ttitik potong pada diagram kartesius.

$$
\begin{array}{rlrl}
\bar{X}=\frac{\sum \mathrm{xi}}{\mathrm{n}} & \overline{\bar{Y}} & =\frac{\sum \overline{\bar{F}} \mathrm{Y} \overline{\overline{1}}}{\mathrm{k}} \\
& =\frac{39,43}{10} & & =\frac{41,28}{10} \\
& =3.94 & & =4,13
\end{array}
$$

Posisi titik (X) atau kinerja berada pada titik 3,94 dan unruk titik (Y) atau harapan berada pada titik 4.13 yang menhasilkan diagram Importance Performace Analysis seperti Gambar 1.

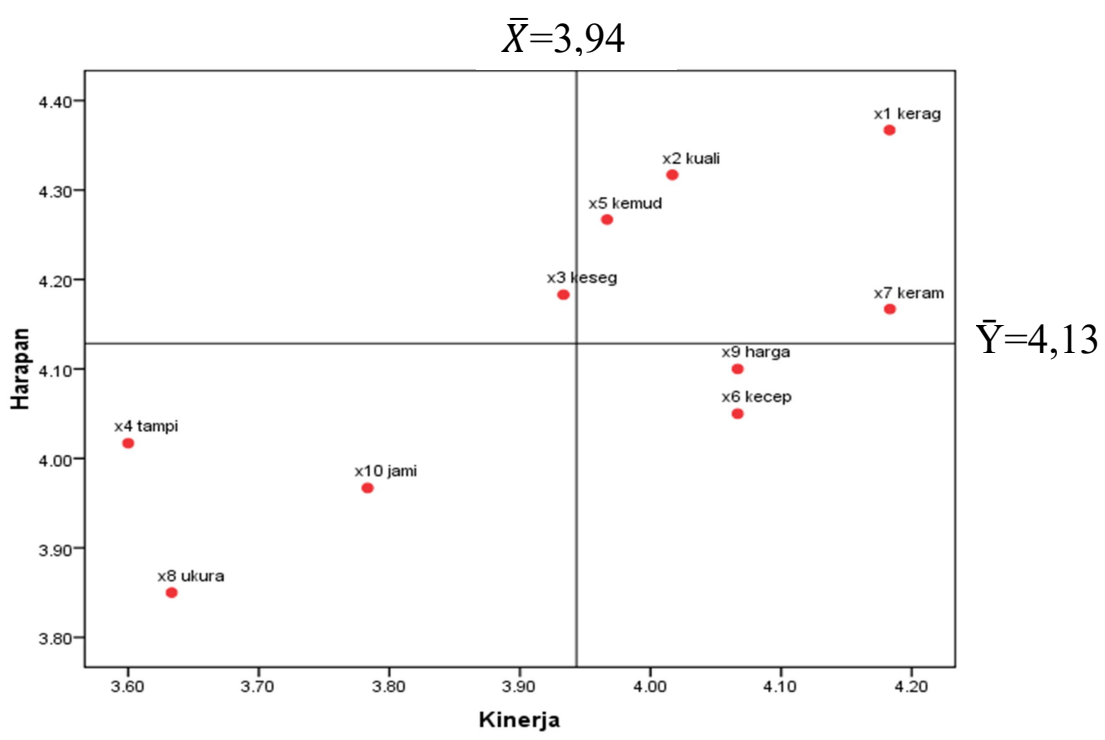

Gambar 1. Diagram Kartesius Hasil Importance Performance Analysis (IPA) 
Kuadran pertama (Prioritas utama) pada hasil analisis Importance Performance Analysis (IPA) di atas menunjukkan area sangat penting. Atribut yang berada pada kuadran ini dianggap penting oleh konsumen, tetapi kinerjanya masih lebih rendah dari harapan konsumen. Dengan demikian, atributatribut tersebut harus diprioritaskan untuk diperbaiki oleh PO Ellfaz Fruits \& Vegetables sehingga kinerja atribut ini meningkat dan memenuhi harapan konsumen. Atribut yang terdapat pada kuadran pertama adalah kesegaran produk.

Atribut keragaman, kualitas produk, kemudahan dan keramahan berada pada kuadran kedua (pertahankan prestasi) yang artinya atribut-atribut ini dianggap sangat penting bagi konsumen dan memiliki tingkat kinerja atribut yang tinggi. Oleh karena itu, atribut-aribut tersebut harus terus dipertahankan oleh PO Ellfaz Fruits \& Vegetables.

Kuadran ketiga (prioritas rendah) ditempati oleh atribut tampilan produk, ukuran produk dan jaminan. Atribut pada kuadran ini dianggap rendah atau kurang penting oleh konsumen dan kinerjanya juga kurang baik. PO Ellfaz Fruits \& Vegetables perlu mempertimbangkan untuk memperbaiki atribut-atribut tersebut karena manfaat yang dirasakan konsumen sangat kecil.

Atribut kecepatan dan harga berada pada kuadran keempat (berlebih), artinya area sangat puas bagi konsumen, namun harapan konsumen sangat rendah. Atribut yang berada pada kuadran ini dianggap kurang penting oleh konsumen namun dirasa terlalu berlebih dalam kinerjanya. Oleh karena itu, meskipun kinerja sayuran atas atribut-atribut dalam kuadran ini baik, justru dianggap sesuatu yang berlebih. Pihak PO Ellfas Fruits \& Vegetables hanya perlu menjaga kinerja atribut-atribut ini, untuk peningkatan kinerja atribut ini sebaiknya tidak perlu dilakukan.

\section{KESIMPULAN DAN SARAN}

\section{Kesimpulan}

Pada penelitian ini karakteristik konsumen yang membeli sayuran di PO. Ellfaz Fruits \& Vegetables didominasi oleh perempuan (90\%), dengan rentang usia 22-31 tahun (47\%), berpendidikan terakhir diploma/sarjana (S1, S2 atau S3) sebanyak 78\%, berprofesi sebagai PNS/ABRI (33\%), dan berpendapatan di atas Rp. 5.000 .000 (40\%). Berdasarkan hasil perhitungan dan pengukuran tingkat kepuasan konsumen terhadap atribut sayuran di PO Ellfaz fruits \& Vegetables 
yaitu sebesar 78,97\% yang menunjukkan konsumen merasa puas dengan kinerja dari perusahaan. Sedangkan atributatribut yang disukai oleh konsumen ialah atribut yang berada pada kuadran II yaitu keragaman sayuran, kualitas sayuran, kemudahan dan keramahan.

\section{Saran}

1. Diharapkan bagi pihak PO Ellfaz Fruits \& Vegetables, atribut bentuk harus diprioritaskan untuk diperbaiki, sehingga kinerja pada atribut ini memenuhi harapan konsumen. Atribut keragaman, kualitas, kemudahan dan keramahan perlu dipertahankan kinerjanya karena merupakan kekuatan atau keunggulan PO Ellfaz Fruits \& Vegetables.

2. Diharapkan bagi peneliti selanjutnya dapat mengembangkan penelitian ini dengan menambah atribut-atribut lain yang dapat mendukung penelitian selanjutnya.

\section{DAFTAR PUSTAKA}

Badan Pusat Statistik. 2016. Pemantauan Ketahanan Pangan. Fokus Tren Konsumsi dan Produksi Buah dan Sayur. Jakarta:BPS.
Departemen Pertanian, 2008. Kebijakan Teknis Program Pengembangan Usaha Agribisnis Perdesaan. Jakarta: Departemen Pertanian.

Ernst and Young, 1999 dalam Ching dan Dolakia, 2003.

Guswanto B, Gumilar I, dan Hamdani H. 2012. Analisis Indeks Kinerja Pengelola dan Indeks Kepuasan Pengguna di Pelabuhan Perikanan Samudera Nizam Zachman Jakarta. Jurnal Perikanan dan Kelautan Vol.3 No. 4 ISSN : 2088-3137. Universitas Padjajaran Bandung.

Irawan, 2003. 10 Prinsip Kepuasan Pelanggan. Cetakan Kelima. Jakarta: Elex Media Kompitudo.

Rangkuti, Freddy. 2003. Analisis SWOT Teknik Membedah Kasus Bisnis. Jakarta: Gramedia Pustaka Utama.

Supranto, Johannes. 2006. Pengukuran Tingkat Kepuasan Pelanggan Untuk Menaikkan Pangsa Pasar. Jakarta: PT Asdi Mahasatya.

Sugiyono, 2012. Metode Penelitian Kuantiatif, Kualitatif dan $R \& D$. Cetakan ke-17. Bandung: Alfabeta.

Sugiyono, 2011. Metode Penelitian Kuantiatif, Kualitatif dan $R \& D$. Bandung: Alfabeta.

Tjiptono, 2001. Manajemen Pemasaran dan Analisa Perilaku Konsumen. Yogyakarta: BFEE.

Tjiptono, 2008. Strategi Pemasaran, Edisi III. Yogyakarta : Andi Offset.

Tjiptono, Fandy \& Gregorius, C.(2006). Service Quality \& Satisfaction.Yogyakarta: Andi Offse.

Rangkuti, Freddy. 2003. Analisis SWOT Teknik Membedah Kasus Bisnis. Jakarta: Gramedia Pustaka Utama. 